\title{
Predictors of weight loss outcomes in obesity care: results of the national ACTION study
}

Nikhil V. Dhurandhar ${ }^{1 *}$, Theodore Kyle ${ }^{2}$, Boris Stevenin ${ }^{3}$, Kenneth Tomaszewski ${ }^{4}$ and The ACTION Steering Group

\begin{abstract}
Background: A key objective of this study was to examine obesity care attitudes and behaviors of people with obesity (PwO) and determine independent factors associated with a self-reported sustained weight loss success outcome.
\end{abstract}

Methods: An online survey was conducted in 2015 among 3008 U.S. adult PwO (BMI $\geq 30$ through self-reported height and weight). Multivariate logistic models explained variation in weight loss success, defined as $\geq 10 \%$ weight loss in previous 3 years and maintained for $\geq 1$ year.

Results: Controlling for weight changes over time, we found significant associations between self-reported weight history and weight loss success. PwO who had personal motivation to lose weight, were willing to talk to a diabetes educator about their weight, who had their weight loss attempts recognized by a healthcare provider, and were diagnosed with "obesity" or "overweight" were more likely to report having success losing weight.

Conclusions: This study does not determine causality, but suggests motivation and engagement with PwO may impact weight loss, and presents a basis for assessing the mechanism involved. Determining such mechanisms may identify important targets to improve obesity treatment outcomes.

Trial registration: This study is registered with ClinicalTrials.gov, number NCT03223493, https://clinicaltrials.gov/ct2/ show/NCT03223493. Registered July 17, 2017 (retrospectively registered).

Keywords: People with obesity, Obesity attitudes, obesity management, Weight-loss success

\section{Background}

Obesity is a serious, complex, and chronic disease that requires lifelong management [1-3]. This multifactorial condition is widely prevalent; more than one-third of the United States adult population has obesity, as defined by a BMI $\geq 30$ [4]. Achieving a sustained weight loss can be difficult for many people with obesity ( $\mathrm{PwO}$ ) [5-8]. Many modifiable and non-modifiable factors may contribute to successful weight loss, including genetics, weight loss approaches, psychosocial factors, motivation levels, and available support system [9-14]. It is important to focus on modifiable factors contributing to weight loss success.

To better understand factors associated with weight loss outcomes, we examined survey results in a nationally

\footnotetext{
* Correspondence: Nikhil.Dhurandhar@ttu.edu

${ }^{1}$ Texas Tech University, Lubbock, TX, USA

Full list of author information is available at the end of the article
}

representative sample of persons with obesity $(\mathrm{PwO})$ from the ACTION (Awareness, Care, and Treatment In Obesity maNagement) Study [15]. A key objective of ACTION was to determine independent factors associated with a self-reported sustained weight loss success outcome among PwO. This study provides insight into the demographic, behavioral, and attitudinal factors associated with weight loss among $\mathrm{PwO}$ and actions health care providers (HCPs) may take to help their patients with obesity increase their chances for weight loss success.

\section{Methods \\ Study design}

This cross-sectional study, sponsored by Novo Nordisk Inc. and approved by an Institutional Review Board [16], was conducted in 2015 (from October 29th to November 12th) among US adults age $\geq 18$ with obesity (defined as

(c) The Author(s). 2019 Open Access This article is distributed under the terms of the Creative Commons Attribution 4.0 International License (http://creativecommons.org/licenses/by/4.0/), which permits unrestricted use, distribution, and 
self-reported body mass index (BMI) of $30 \mathrm{~kg} / \mathrm{m}^{2}$ or higher). PwO responded to an online survey which assessed obesity-related attitudes and behaviors and was developed based on literature review and qualitative research [17]. Respondent-level weighting was applied [18] to ensure the sample was representative of the U.S. population [19]. Except for participant characteristics, the data presented in this paper are weighted unless otherwise specified. A detailed methodological description has been previously published [15]. Five-point end-anchored scales assessed agreement, where "1" meant "do not agree at all," and "5" meant "completely agree." Responses of " 4 " or " 5 " were coded and reported as "agree" unless otherwise noted.

\section{Data analysis}

A self-reported weight loss success outcome was defined within the survey instrument explicitly. A multivariate logistic regression model assessed variation in "weight loss success" (dependent variable) defined as: 1) Weight loss history: at least $10 \%$ weight loss in the previous 3 years; and 2) Success: weight loss at the time of survey response that was maintained for at least 1 year (by respondent self-report).

Bivariate associations between the outcome of interest and 140 possible independent variables were assessed and grouped into 3 domains: demographic, attitudinal, and behavioral. Independent variables with large bivariate effect sizes and significant practical implications were identified. Variance inflation factors were used to assess the degree of multicollinearity present among the remaining 32 independent variables; no variables were removed at this step.

To achieve a parsimonious model, a purely statistical approach was used to reduce the inputs. A Bayesian variable selection approach was used to overcome the biases and shortcomings of stepwise variable selection. A logistic regression model was estimated using the nine remaining independent variables; two were removed for non-statistical significance and high degree of correlation with other independent variables (feelings after most recent discussion of weight with HCP: supported; barriers to initiating a weight loss effort: my lack of motivation, respectively). Seven characteristics taken from demographic, attitudinal and behavioral survey domains were included in the model. Six of the seven variables included in the final model were statistically significant at the $5 \%$ level of significance; discussing weight with a diabetes educator was not statistically significant but increased the stability of the model.

A sensitivity analysis was conducted to determine the independent impact each variable in the model has on the average chance of being successful in losing weight and keeping it off for 1 year. To conduct the sensitivity analysis, we implemented the following procedure for each independent variable in the model: 1) for categorical variables, a 1000-iteration bootstrap sample (a technique of randomly sampling the data and iteratively calculating the statistics to generate more accurate population estimates) was performed to calculate the mean predicted probability of sustained weight loss success for incremental improvements and deteriorations of 1 to $100 \%$; 2) for continuous variables, the mean predicted probability of sustained weight loss success was calculated for incremental improvements and deteriorations of 1 to $100 \%$.

\section{Results}

Adult PwO ( $n=3008)$ completed online surveys; characteristics for $\mathrm{PwO}$ are displayed in Table 1.

Slightly less than one-quarter of $\mathrm{PwO}(23 \%)$ reported at least $10 \%$ weight loss from maximum weight in the past 3 years to their current weight. Among these $\mathrm{PwO}$, $44 \%$ reported having maintained weight loss for at least 1 year, representing $10 \%$ of all $\mathrm{PwO}$ surveyed.

\section{Multivariate model results}

Model results are described in Table 2. The odds of sustained weight loss success are compared to a base case $\mathrm{PwO}$ who weighed 248 pounds 1 year ago and 221 pounds 10 years ago, and who has been formally diagnosed with obesity, reports their HCP not often recognizing the PwO's previous weight management efforts, does not agree that he/she is motivated to lose weight, does not agree that his/her lack of motivation is a barrier to initiating a weight loss effort, and has not discussed or would not want to discuss weight with a diabetes educator.

The model's statistical fit was assessed by using the model diagnostics of accuracy (percentage of the time the model accurately classifies a $\mathrm{PwO}$ as successful in

Table 1 Sample characteristics (unweighted)

\begin{tabular}{ll}
\hline & $\begin{array}{l}\text { People with Obesity } \\
(\mathrm{n}=3008)\end{array}$ \\
\hline Characteristics & $n(\%)$ \\
Sex & \\
$\quad$ Male & $1378(46)$ \\
Female & $1630(54)$ \\
Age & \\
Mean Age in Years (SD) & $54.4(14.3)$ \\
BMI Classification & \\
Class I (BMI 30-<35) & $1304(43)$ \\
Class II (BMI 35-<40) & $896(30)$ \\
Class III (BMI $\geq 40)$ & $808(27)$ \\
BMI &
\end{tabular}

SD Standard deviation, BMI Body mass index 
Table 2 Multivariate Logistic Model Results - Variables and Odds of Sustained Weight Loss Success Compared to Base Case PwO

\begin{tabular}{|c|c|c|c|c|c|}
\hline Variable Type & Variable Description & $\begin{array}{l}\text { Variable } \\
\text { Specification }^{\text {b }}\end{array}$ & $\begin{array}{l}\text { Coefficient } \\
\text { (Standard } \\
\text { Error) }\end{array}$ & $\begin{array}{l}\text { Odds Ratio and 95\% } \\
\text { Confidence Interval }\end{array}$ & $\begin{array}{l}\text { PwO } \\
\text { Affected }\end{array}$ \\
\hline Intercept & N/A & Constant & $-3.67(0.4847)$ & N/A & $\mathrm{N} / \mathrm{A}$ \\
\hline Demographic & Weight History 1 year ago & Continuous & $-0.01(0.0026)^{* * *}$ & $0.99(0.99-1.00)^{c}$ & Mean $=248 \mathrm{lbs}$ \\
\hline Demographic & Weight History 10 years ago & Continuous & $-0.02(0.0021)^{* * *}$ & $1.02(1.01-1.02)$ & Mean $=221 \mathrm{lbs}$ \\
\hline Demographic & Formal diagnosis of obesity & $\begin{array}{l}\text { No, Not sure }[2,3]->1 \\
\text { Yes }[1]->0\end{array}$ & $-0.45(0.1902)^{*}$ & $0.64(0.44-0.92)$ & $\begin{array}{l}\text { No/Not sure }[2,3] \\
=44 \%\end{array}$ \\
\hline Attitudinal & $\begin{array}{l}\text { When discussing your weight } \\
\text { with your HCP, how often do } \\
\text { they recognize your previous } \\
\text { weight management efforts? }\end{array}$ & $\begin{array}{l}\text { Often }[4,5]->1 \\
\text { Not often }[1-3]->0\end{array}$ & $0.69(0.1687)^{* * *}$ & $1.99(1.43-2.77)$ & Often $[4,5]=39 \%$ \\
\hline Attitudinal & $\begin{array}{l}\text { Attitudes toward weight loss: } \\
\text { I am motivated to lose weight }\end{array}$ & $\begin{array}{l}\text { Agree }[4,5]->1 \\
\text { Do not agree }[1-3]->0\end{array}$ & $0.59(0.1746)^{* * *}$ & $1.81(1.28-2.54)$ & Agree $[4,5]=45 \%$ \\
\hline Attitudinal & $\begin{array}{l}\text { Barriers to initiating a weight } \\
\text { loss effort: my lack of motivation }\end{array}$ & $\begin{array}{l}\text { Agree }[4,5]->1 \\
\text { Do not agree }[1-3]->0\end{array}$ & $-0.49(0.1699)^{* *}$ & $0.61(0.44-0.86)$ & Agree $[4,5]=52 \%$ \\
\hline Behavioral & $\begin{array}{l}\text { HCPs discussed weight with/ } \\
\text { would discuss weight with: }\end{array}$ & $\begin{array}{l}\text { Yes }[1]->1 \\
\text { No }[2]->0\end{array}$ & $0.20(0.2317)$ & $1.22(0.78-1.93)$ & Yes $[1]=10 \%$ \\
\hline
\end{tabular}

Model Fit Statistics

diabetes educator

Mean (95\% Confidence Interval)

Accuracy $\quad 70 \%(65-74 \%)$

Specificity $\quad 70 \%(54-79 \%)$

Sensitivity $\quad 66 \%(52-75 \%)$

PwO People with Obesity, HCP Healthcare Provider, Lbs Pounds

${ }^{a}$ Base Case PwO: weight 1 year ago $=248$ lbs., weight 10 years ago $=221 \mathrm{lbs}$.; formal diagnosis of obesity =yes, HCP recognizes previous weight management efforts = not often, I am motivated to lose weight = do not agree, my lack of motivation is a barrier to a weight loss effort = do not agree, discussed/would discuss weight with diabetes educator $=$ no

${ }^{\mathrm{b}}$ Answer categories and scale definitions

${ }^{*} p<0.05,{ }^{* *} p<0.01,{ }^{* * *} p<0.001$

'Due to rounding; unrounded value is $<1.00$

achieving sustained weight loss), specificity (percentage of failed weight loss attempts accurately predicted by the model), and sensitivity (percentage of successful weight loss attempts accurately predicted by the model). Individual observations were assessed for their degree of leverage/influence and residuals were assessed via a studentized residuals vs. fitted probability plot. Higher leverage points were dispersed throughout the fitted probability space - these points were not overly influencing prediction to one class or the other. The points with the highest residual error were all cases of successful weight loss and occurred at the lower end of the fitted probability scale (i.e. 0.0-0.2) indicating that a low probability threshold should be used for classification of successful weight loss. A threshold of 0.11 was identified as the boundary that best-balanced model accuracy (70\%), sensitivity (68\%), and specificity (70\%). Two-thousand (2000) splits of the data into $80 \%$ training and $20 \%$ test showed stable model performance at this threshold with values as shown in Table 2.

Self-reported weight 1- and 10- years prior were both significantly associated with sustained weight loss success, controlling for beginning and ending weight (1 and 10 years prior, respectively); i.e., the model controlled for variation associated with varying weights. On average, each additional pound of weight 1 year ago predicted a decrease in the success odds by $\sim 1 \%$; however, each additional pound of weight 10 years ago increased the odds of success by a factor of 1.02 (increasing the odds by $\sim 2 \%$ ).

Not formally being diagnosed with obesity was associated with a decrease in PwO's odds of sustained weight loss success by a factor of 0.64 . $\mathrm{PwO}$ who felt their lack of motivation was a barrier to weight loss had lower odds of reporting success, even after controlling for other factors such as their changes in weight and attitudes towards initiating weight loss.

Discussion with a diabetes educator (or willingness to discuss) was associated with increased odds of sustained weight loss success by a factor of 1.22 . HCPs' recognition of PwO's previous weight loss efforts and PwO's self-reported motivation to lose weight had the greatest impact on the odds of success, increasing them by a factor of 1.99 and 1.81 , respectively.

To further illustrate how the odds of successful sustained weight loss may be manifested at the 
individual level, we explored several hypothetical scenarios (Table 3).

The presence of PwOs' motivation in the absence of a formal obesity diagnosis or recognition of previous weight management efforts ("Inactive HCP; Motivated PwO") was associated with a predicted 19\% decrease in the rate of sustained weight loss success compared with the population average. A $\mathrm{PwO}$ who was unmotivated to lose weight but receives a formal diagnosis, has a discussion with a diabetes educator, and receives recognition from an HCP ("Active HCP, Unmotivated PwO") is predicted to have a greater rate of success, with a $6 \%$ increase over the population average prediction. Finally, $\mathrm{PwO}$ who receive recognition of previous weight loss efforts from HCPs and report feeling motivated ("Encouraging HCP; Motivated $\mathrm{PwO}$ ") are more likely to have success, with a $98 \%$ increased likelihood compared with the population average.

\section{Sensitivity analysis}

In the sensitivity analysis described above, we found that increasing obesity diagnoses rates and discussions with a diabetes educator have the least independent influence on the predicted success rate across the sample. Increasing the rate of diagnosis or discussions with a diabetes educator by $50 \%$ results in an absolute change of $<1 \%$ point from the baseline prediction of sustained weight loss success of $11.5 \%$ (baseline prediction is the model's estimated sustained weight loss success at the means for each independent variable). A decrease in the prevalence of PwO's self-reported motivation or a reduction in the prevalence of motivation as a barrier by $50 \%$ results in an absolute change of $1.4 \%$ points and $1.1 \%$ points from the baseline prediction, respectively. Increasing the proportion of $\mathrm{PwO}$ whose previous weight management effort is recognized by HCPs by $50 \%$ improves the average chance of success by $1.8 \%$ points.

Although the absolute point changes in the average predictive probabilities are modest, these translate to substantial population level increases (number of $\mathrm{PwO}$ ) relative to the average baseline rates of weight loss success (Fig. 1). Increasing the rate at which a PwO's previous weight management efforts are recognized by an HCP by $25 \%$ is predicted to result in an $8 \%$ improvement in the rate of success. The same level of increase in a PwO's self-reported motivation to lose weight is associated with a $6 \%$ improvement in the weight loss success rate.

\section{Relationship between BMI and attitudes towards weight loss discussions}

Looking outside the model, we further sought to understand if weight loss discussions and attitudes towards them are associated with the BMI of $\mathrm{PwO}$. Evaluating PwO by obesity class (Class I: BMI $30-<35$, Class II: BMI 35-<40, Class III: BMI $\geq 40$ ) [20], we found significant differences in attitudes and behaviors. PwO with Class III Obesity were significantly more likely $(30 \%, 95$ CI [26-35\%]) than those with Class I (21\%, 95 CI [18$24 \%], p<.001)$ or Class II Obesity $(22 \%, 95$ CI [18$25 \%$ ], $p<.001)$ to report having sought support from their HCP regarding weight management after they have tried losing weight on their own with no success. $\mathrm{PwO}$ with Class I or Class II Obesity (39.1\%, 95 CI [35-43\%] and 39\%, $95 \mathrm{CI}$ [35-43\%], respectively) were significantly

Table 3 Practical Scenarios and Impact on Baseline Prediction of the Logistic Model ${ }^{a}$

\begin{tabular}{|c|c|c|c|}
\hline \multicolumn{4}{|l|}{ Practical Scenarios Defined } \\
\hline Variable Description & $\begin{array}{l}\text { Active HCP; } \\
\text { Unmotivated PwO }\end{array}$ & $\begin{array}{l}\text { Inactive } \mathrm{HCP} \\
\text { Motivated PwO }\end{array}$ & $\begin{array}{l}\text { Encouraging } \mathrm{HCP} \text {; } \\
\text { Motivated PwO }\end{array}$ \\
\hline Formal diagnosis of obesity & Yes & No & No \\
\hline $\begin{array}{l}\text { HCP often recognizes PwO's previous } \\
\text { weight management efforts }\end{array}$ & Yes & No & Yes \\
\hline PwO motivated to lose weight & No & Yes & Yes \\
\hline PwO lack of motivation is a barrier & Yes & No & No \\
\hline $\begin{array}{l}\text { PwO discussed weight with/would discuss } \\
\text { weight with diabetes educator }\end{array}$ & Yes & No & Yes \\
\hline Practical Scenario Impact & $\begin{array}{l}\text { Active HCP; } \\
\text { Unmotivated PwO }\end{array}$ & $\begin{array}{l}\text { Inactive HCP; } \\
\text { Motivated PwO }\end{array}$ & $\begin{array}{l}\text { Encouraging } \mathrm{HCP} \text {; } \\
\text { Motivated } \mathrm{PWO}\end{array}$ \\
\hline $\begin{array}{l}\text { Predicted Probability of Sustained Weight } \\
\text { Loss Success }\end{array}$ & $12.20 \%$ & $9.36 \%$ & $22.84 \%$ \\
\hline \% Change from Population Average Prediction & $6 \%$ & $-19 \%$ & $98 \%$ \\
\hline
\end{tabular}

PwO People with Obesity, HCP Healthcare Provider

${ }^{\text {a }}$ Population average prediction $=11.5 \%$; weight history 1 year ago and 10 years ago were set to the population average of 248 pounds and 221 pounds, respectively 


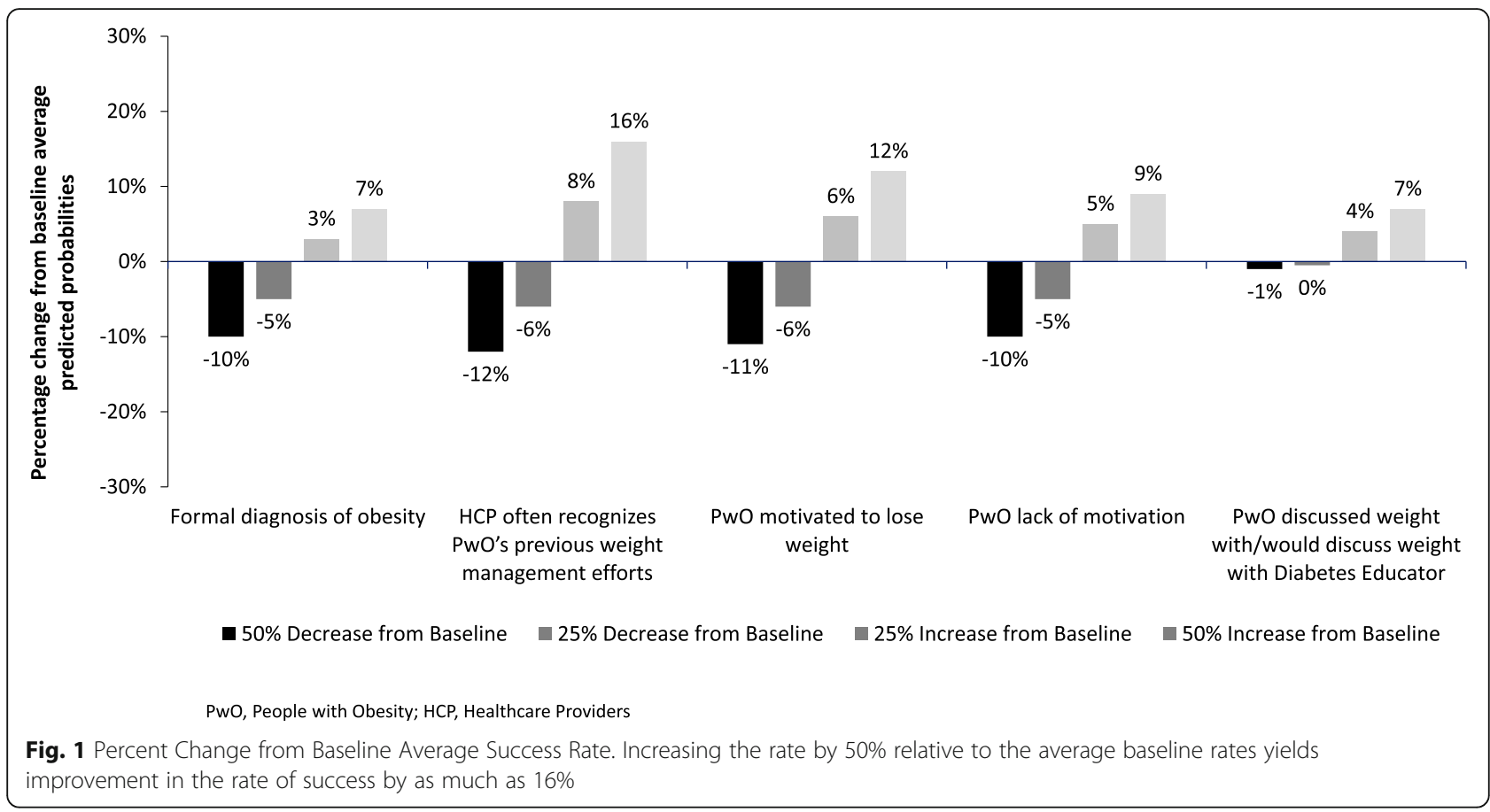

more likely than those with Class III Obesity (31\%, 95 CI $[27-35 \%])$ to report not seeking support from their $\operatorname{HCP}(p=.002$ and $p=.003$, respectively). Conversations with HCPs differed by obesity class; when asked who typically brings up weight during the appointment, $\mathrm{PwO}$ with Class I Obesity were significantly more likely to say they, rather than their HCP, typically started the conversation about their weight $(51 \%, 95 \mathrm{CI}[47-55 \%]$ than those with Class II $(45 \%, 95 \mathrm{CI}[41-50 \%, p=0.026]$ and Class III Obesity (43\%, 95 CI [39-47\%], $p=.002$. Those with Class II and III Obesity were significantly more likely than those with Class I Obesity to report negative feelings of "embarrassed," "discouraged," and "blamed" after their most recent discussion with their HCP. When asked how their HCP could better support them in achieving a healthy weight, $\mathrm{PwO}$ with Class II and Class III Obesity were significantly more likely than those with Class I Obesity to cite "be more understanding of the challenges of losing weight," "be more understanding of the challenges with living with obesity," and "refer me to a dietitian."

\section{Discussion}

Although causation between the self-reported factors and weight loss outcomes cannot be implied from this observational study, the results from these analyses provide greater insight into factors that may predict a PwO's chance of being successful in weight management, including the role of the HCP as one of these factors. The study offers an opportunity to understand the expectations and efforts of $\mathrm{PwO}$ around their struggle with the disease. The multivariate model revealed a sizable impact on sustained weight loss success on an individual level; the sensitivity analysis demonstrated a lower impact on a population level at the levels we tested. However, these small changes resulted in substantial relative impacts when considered at the population level.

Higher self-reported weight 1 year ago had a moderately negative impact on successful weight loss outcomes, indicating that $\mathrm{PwO}$ are more likely to achieve success over a longer period. This is supported by the positive impact of a higher weight on a longer time scale of 10 years. The greater the weight 1 year ago, the harder it is for $\mathrm{PwO}$ to be successful in their weight management efforts. More recent weight gain may be more of a challenge to $\mathrm{PwO}$; struggling with obesity for a longer time may be a driving factor in $\mathrm{PwO}$ being more determined to make a serious weight loss attempt. Inversely, recent progress towards weight management goals (lower self-reported weight a year ago) may be a selfreinforcing mechanism: being closer to a goal in the near term makes reaching that goal more feasible. These variables can more generally be considered "control" variables, thus ensuring other model parameters have an independent effect after controlling for weight history.

Discussions with HCPs who acknowledge and support previous weight loss efforts were reportedly associated with substantially improved odds of an individual PwO's successful weight loss attempt. Despite relatively low levels of improvement in the population, recognizing PwO's weight loss attempts would require marginal 
efforts by HCPs and may have an exponential positive impact on the PwO-HCP relationship and the individual PwO's chances for success. We hypothesize that the individual success rate improvements when HCPs engage in this behavior with their patients is driven by communicating support and encouragement for the patient.

Motivation is a key to PwO being successful in sustained weight loss [21-23]; at the start and during weight loss efforts, motivation remains independently relevant. An individual PwO's lack of motivation, specifically with respect to initiating weight loss efforts, was associated with poorer outcomes. Additionally, $\mathrm{PwO}$ who were motivated during the weight loss process see a very large improvement in their odds of success. However, our model indicates that lack of motivation may be overcome or mitigated with proactive measures by an HCP including diagnosing patients with obesity, recognizing previous weight management efforts, and discussion with a diabetes educator, regardless of how successful the PwO may have been. This study suggests that even when a $\mathrm{PwO}$ is less motivated and perceives their lack of motivation is a barrier to sustained weight loss, engaged $\mathrm{HCP}$ interaction may result in "average" or even above average outcomes at the individual level; however, this relationship would need to be further explored in other research.

Formally diagnosing individual patients with obesity is also associated with weight loss success; this research may encourage $\mathrm{HCPs}$ to be engaged in supporting $\mathrm{PwO}$ in their weight loss efforts. As such, an appropriate diagnosis is a required first step for treating any disease. In addition, making a diagnosis may also be an effective avenue for HCPs to start the obesity management conversation with their patients with obesity, particularly those who have struggled with obesity for a long time.

Having discussed weight with, or being willing to discuss weight with a diabetes educator is also positively associated with successful weight loss, although the lack of independent statistical significance suggests this result is directional. The impact of discussing weight with a diabetes educator speaks to the benefit of additional support services and resources that can address co-morbid conditions associated with obesity.

Having regular discussions with $\mathrm{PwO}$ about their weight and weight management efforts is an important factor in effective obesity management $[24,25]$. Understanding that PwO tend to seek care from their HCP only after their own self-management attempts have failed, as seen in this study, could help address and reduce stigma and bias in treating PwO. Recognizing previous weight management efforts could be an effective tool in ensuring weight management discussions are positive in nature and reduce negative feelings among $\mathrm{PwO}$, especially those with Class II or Class III Obesity. By acknowledging the daily and often life-long struggles of $\mathrm{PwO}, \mathrm{HCPs}$ may convey a greater sense of support that may help increase PwO's motivation and chances of weight loss success. Lastly, treating obesity as a multi-factorial disease by ensuring $\mathrm{PwO}$ have access to a broader clinical team may support patients' obesity management efforts.

Limitations of this study have been previously reported including the cross-sectional design and self-reported nature of height and weight being potential limiting factors [15]. An additional limitation was the use of a self-reported assessment of motivation rather than a validated instrument specifically designed to assess this factor. Selection of a logistic regression model assumes that the probability of sustained successful weight loss is roughly approximated by a logistic distribution in the population; however, logistic regression is the most common empirical model of binary dependent variables across disciplines [26].

\section{Conclusion}

Weight loss success was consistent with PwO-reported weight loss history; predictions from our logistic regression model consistently replicate success rates based on PwO-reported weight loss history. Even after controlling for weight history, motivation in addition to support from HCPs is associated with weight loss success among PwO. This study highlights the role that personal motivation and engagement of $\mathrm{PwO}$ may play in weight loss success and sets the stage for further investigation of these factors in predicting success. Such an understanding may aid in the identification of key approaches to improve obesity management and outcomes.

\section{Abbreviations}

ACTION Study: Awareness, Care, and Treatment In Obesity maNagement; BMI: Body Mass Index; Cl: Confidence Interval; HCP: Healthcare Provider; Lbs: Pounds; PwO: People with Obesity; SD: Standard deviation

\section{Acknowledgements}

We thank the additional members of the ACTION Steering Group: Lee M. Kaplan (Massachusetts General Hospital, Boston, MA, USA; Kaplan.Lee@mgh. harvard.edu), Angela Golden (NP from Home, LLC., Munds Park, AZ, USA; npfromhome@gmail.com), Kimberly Jinnett (Integrated Benefits Institute, San Francisco, CA, USA; kimberly.jinnett@ucsf.edu), Ronette L. Kolotkin (Quality of Life Consulting, Durham, NC, USA; rkolotkin@qualityoflifeconsulting.com), Michelle Look (San Diego Sports Medicine and Family Health, San Diego, CA, USA; lookmi808@gmail.com), Joseph Nadglowski (Obesity Action Coalition, Tampa, FL, USA; jnadglowski@obesityaction.org), Patrick M. O'Neil (Medical University of South Carolina, Charleston, SC, USA; oneilp@musc.edu), Thomas Parry (Integrated Benefits Institute, San Francisco, CA, USA; tparry@ibiweb. org), and Søren Kruse Lilleøre (Novo Nordisk A/S, Søborg, Denmark; sqkl@novonordisk.com). We also thank Rebecca Hahn of KJT Group Inc. for medical writing assistance and support.

\section{Authors' contributions}

$N D, T K, K T$ designed the study and developed the study materials in collaboration with the other members of the ACTION Steering Group. All authors provided input into the data analyses, contributed to writing the manuscript, and read and approved the final manuscript. The ACTION Steering Group designed the study and developed the study materials.

Funding

Novo Nordisk Inc. financed the design of the study, data collection, analysis, and interpretation of data as well as the writing of the manuscript. The ACTION Steering Group (which is comprised of subject matter experts and 
one employee of the funder, Søren Kruse Lilleøre) was independently responsible for the design of the study, interpretation of the data, and writing of the manuscript.

\section{Availability of data and materials}

Data will be shared with bona fide researchers submitting a research proposal requesting access to data. Data will be shared for use as approved by the Independent Review Board according to the IRB Charter (see novonordisk-trials.com). Access request proposal form and the access criteria can be found at novonordisk-trials.com. Individual participant data will be shared in data sets in a de-identified/-anonymized format. The data will be made available on a specialized SAS data platform.

\section{Ethics approval and consent to participate}

Ethics approval was obtained from Copernicus Review Board (KJT1-15-499) Prior to completing surveys, respondents provided informed consent electronically. The paper contains no identifying information.

\section{Consent for publication}

Not applicable.

\section{Competing interests}

Dr. Dhurandhar reports personal fees from Novo Nordisk during the conduct of the study and personal fees from Novo Nordisk outside the submitted work. He has also received an investigator-initiated grant from Novo Nordisk. Mr. Kyle reports personal fees from Novo Nordisk, during the conduct of the study; personal fees from Eisai, personal fees from NutriSystem, outside the submitted work.

Dr. Stevenin is an employee of Novo Nordisk, Inc.

Dr. Tomaszewski reports consulting fees from Novo Nordisk during the conduct of the study.

\section{Author details}

${ }^{1}$ Texas Tech University, Lubbock, TX, USA. ${ }^{2}$ ConscienHealth, Pittsburgh, PA, USA. ${ }^{3}$ Novo Nordisk Inc., Plainsboro, NJ, USA. ${ }^{4}$ KJT Group, Inc., Honeoye Falls, NY, USA.

\section{Received: 13 February 2019 Accepted: 23 September 2019}

Published online: 30 October 2019

\section{References}

1. Bray G, Kim KK, Wilding JPH. Obesity: a chronic relapsing progressive disease process. A position statement of the world obesity federation. Obes Rev. 2017. https://doi.org/10.1111/obr.12551.

2. AMA Declares Obesity a Disease 2013 [Available from: http://www. medscape.com/viewarticle/806566.

3. Rippe JM, Crossley S, Ringer R. Obesity as a chronic disease: modern medical and lifestyle management. J Am Diet Assoc. 1998;98(10, Supplement):S9-S15.

4. Prevalence of obesity among adults, $\mathrm{BMI} \geq 30$, age-standardized estimates by country. http://apps.who.int/gho/data/view.main.CTRY2450A?lang=en. Accessed 18 Sept 2018.

5. Kirk SF, Tytus R, Tsuyuki RT, Sharma AM. Weight management experiences of overweight and obese Canadian adults: findings from a national survey. Chronic Dis Injur Canada. 2012;32(2):63-9.

6. Garip G, Yardley L. A synthesis of qualitative research on overweight and obese people's views and experiences of weight management. Clin Obes. 2011;1(2-3):110-26.

7. Burke LE, Swigart V, Turk MW, Derro N, Ewing LJ. Experiences of selfmonitoring: successes and struggles during treatment for weight loss. Qual Health Res. 2009;19(6):815-28.

8. Hindle L, Carpenter C. An exploration of the experiences and perceptions of people who have maintained weight loss. J Hum Nutr Diet. 2011;24(4):342-50.

9. Elfhag $K$, Rössner $\mathrm{S}$. Who succeeds in maintaining weight loss? A conceptual review of factors associated with weight loss maintenance and weight regain. Obes Rev. 2005;6(1):67-85.

10. Wing RR, Phelan S. Long-term weight loss maintenance. Am J Clin Nutr. 2005:82(1 Suppl):222s-5s

11. Gallagher Kl, Jakicic JM, Napolitano MA, Marcus BH. Psychosocial factors related to physical activity and weight loss in overweight women. Med Sci Sports Exerc. 2006;38(5):971-80.
12. Douketis JD, Macie C, Thabane L, Williamson DF. Systematic review of longterm weight loss studies in obese adults: clinical significance and applicability to clinical practice. Int J Obes (Lond). 2005;29:1153.

13. Kruger J, Blanck HM, Gillespie C. Dietary and physical activity behaviors among adults successful at weight loss maintenance. Int J Behav Nutr Phys Act. 2006;3(1):17.

14. Wing RR, Jeffery RW. Benefits of recruiting participants with friends and increasing social support for weight loss and maintenance. J Consult Clin Psychol. 1999;67(1):132-8.

15. Kaplan LM, Golden A, Jinnett K, Kolotkin RL, Kyle TK, Look M, et al. Perceptions of barriers to effective obesity care: results from the national ACTION study. Obesity (Silver Spring). 2018;26(1):61-9.

16. Copernicus Group Independent Review Board [September 2015]. Available from: http://www.cgirb.com/.

17. Kaplan L, Golden A, O'Neil P, et al. Divergence of patient and clinician perceptions of obesity and weight management. Paper presented at: ObesityWeek 2015; 2015/11/02/6. Los Angeles; 2015.

18. Kalton $\mathrm{G}$. Introduction to survey sampling, SAGE University paper series on quantitative applications in the social sciences, series no 07-035. 1st ed. Beverly Hills and London: SAGE Publications, Inc:; 1983.

19. United States Census Bureau. Summary file. 2007-2011 American community survey [internet]. U.S. Census Bureau's American community survey office; 2013. [cited September 2015]. Available from: http://ftp2.census.gov/

20. World Health Organization. Obesity: preventing and managing the global epidemic: report of a WHO consultation. Geneva: World Health Organization; 2000

21. Teixeira PJ, Silva MN, Mata J, Palmeira AL, Markland D. Motivation, selfdetermination, and long-term weight control. Int J Behav Nutr Phys Act 2012;9(1):22

22. Williams GC, Grow VM, Freedman ZR, Ryan RM, Deci EL. Motivational predictors of weight loss and weight-loss maintenance. J Pers Soc Psychol. 1996;70(1):115-26

23. Mata J, Silva MN, Vieira PN, Carraca EV, Andrade AM, Coutinho SR, et al. Motivational "spill-over" during weight control: increased self-determination and exercise intrinsic motivation predict eating self-regulation. Health Psychol. 2009;28(6):709-16.

24. Kushner RF. Clinical assessment and management of adult obesity. Circulation. 2012;126(24):2870-7.

25. Moorhead SA, Coates VE, Gallagher AM, Nolan G, Murphy K, Hazlett DE. Obesity communication among patients by health professionals: findings from the weight care project. Health. 2013;05(08):10.

26. Greene WH. Econometric analysis. Boston. London: Pearson; 2012

\section{Publisher's Note}

Springer Nature remains neutral with regard to jurisdictional claims in published maps and institutional affiliations.

Ready to submit your research? Choose BMC and benefit from:

- fast, convenient online submission

- thorough peer review by experienced researchers in your field

- rapid publication on acceptance

- support for research data, including large and complex data types

- gold Open Access which fosters wider collaboration and increased citations

- maximum visibility for your research: over $100 \mathrm{M}$ website views per year

At BMC, research is always in progress.

Learn more biomedcentral.com/submission 